\title{
Portal Vein Thrombosis in Surgical Ward- What to do: A Technical Review?
}

\author{
M Miah*, P Ravi, R Rajebhosale, R Paul, N Husain, M Al Saramigy and P Thomas \\ Department of General Surgery, Queen's Hospital Burton, UK
}

*Corresponding author: Mohammad Miah, Specialty Doctor, General Surgery, Queen's Hospital Burton, Burton on Trent, DE13 0RB, UK

\section{ARTICLE INFO}

Received: 禽 July 15, 2020

Published: 幽 July 23, 2020

Citation: M Miah, P Ravi, R Rajebhosale, R Paul, N Husain, M Al Saramigy, P Thomas. Portal Vein Thrombosis in Surgical Ward- What to do: A Technical Review? Biomed J Sci \& Tech Res 29(1)-2020. BJSTR. MS.ID.004747.

\section{ABSTRACT}

Splenic and superior mesenteric veins together form the portal vein posterior to the pancreas. Portal vein thrombosis (PVT) is a significant clinicopathologic entity that all surgeons should be aware with. It has significant morbidity and mortality with $1 \%$ incidence in general population. The lifetime possibility of having portal vein thrombosis (PVT) is nearly 1\%. PVT is being diagnosed more often as a result of the increasing usage of numerous advanced imaging modalities. Sonography, CT and magnetic resonance imaging are most used to diagnose PVT. Malignancy, inflammatory conditions of abdomen, trauma, surgery and hypercoagulable states are the most common risk factors causing PVT in surgical patients. PVT ultimately leads to the establishment of many collateral vessels nearby the thrombosed portal vein. Firstline treatment for PVT is therapeutic anticoagulation-it helps prevent the spread of the thrombus. Other therapeutic preferences comprise surgery and interventional radiographic procedures.

Keywords: Portal vein thrombosis; Risk Factors; Virchow's triad; Therapeutic Interventions

\section{Introduction}

Portal vein thrombosis (PVT) is an uncommon event happening with the obstruction or narrowing of the portal vein by a thrombus which is frequently related with the presence of an underlying liver disease or prothrombotic disorders. Portal vein thrombosis (PVT) is a significant clinicopathologic entity that all surgeons should be aware with. It has significant morbidity and mortality with $1 \%$ incidence in general population [1]. It can also follow mesenteric or splenic vein thrombosis. The preponderance of the blood supply to the liver is portal vein comprising up to $75 \%$ of it supplies. The risk factors for PVT are predominantly attributed to Virchow's triad - stasis of blood flow, endothelial injury, and hypercoagulability [2]. PVT occurs with numerous thrombophilic conditions with abdominal pathologies which can be either acute or chronic. PVT is being diagnosed more commonly due to the increasing practice of advanced sonography, computed tomography (CT). The stated lifetime risk of developing PVT in the overall population is roughly 1\%. [3] Nevertheless, the prevalence may be as high as $30 \%$ in patients with hepatocellular carcinoma. In addition, PVT is believed to be causative in nearly $8 \%$ of portal hypertension cases.

\section{Surgical Anatomy}

The portal vein forms posterior to the neck of the pancreas by the union of the splenic and superior mesenteric veins. It ranges from 5.5 to $8 \mathrm{~cm}$ in length, and its diameter is approximately $1 \mathrm{~cm}$. It courses toward the porta hepatis in the free edge of the lesser omentum and receives the cystic, pyloric, accessory pancreatic, and superior pancreaticoduodenal veins, among other tributaries.

\section{Pathophysiology}

Patients with PVT are characterized by a hyperdynamic circulation syndrome like that seen in cirrhosis. Liver enzymes and bilirubin are usually normal or only mildly elevated. Quantitative tests such as indocyan green clearance demonstrates overall slight functional decrease. Liver biopsy results are typically normal, but hemosiderosis associated with portosystemic shunting has 
been described. Cavernous transformation of the portal vein-the development of periportal collaterals nearby the recanalizing or blocked main portal vein - happens with chronic PVT.

\section{Risk Factors}

Risk factors associated with PVT include local or anatomic risk factors and systemic risk factors (Table 1). The presence of risk factors can be established in over $85 \%$ of cases of PVT, with cancer, hepatic cirrhosis, or recent surgery are the most common local risk factors and various thrombophilias are the most common systemic risk factors.

Table 1: Risk factors for Portal vein thrombosis.

\begin{tabular}{|c|c|}
\hline Category & Risk Factors \\
\hline $\begin{array}{l}\text { Intra-abdominal } \\
\text { inflammation }\end{array}$ & $\begin{array}{c}\text { Sepsis, Pancreatitis, Cholangitis, Appendicitis } \\
\text { and so on. }\end{array}$ \\
\hline $\begin{array}{l}\text { Intra-abdominal } \\
\text { Malignancy }\end{array}$ & $\begin{array}{l}\text { Pancreatic malignancy, Hepatocellular } \\
\text { carcinoma, Gastric carcinoma, } \\
\text { Cholangiocarcinoma }\end{array}$ \\
\hline $\begin{array}{l}\text { Prothrombotic } \\
\text { disorder }\end{array}$ & $\begin{array}{c}\text { Antithrombin III Deficiency, Protein } \\
\text { C Deficiency, Protein S Deficiency, } \\
\text { Antiphospholipid syndrome, Factor V Leiden } \\
\text { mutation, Disseminated Intravascular } \\
\text { coagulation and so on. }\end{array}$ \\
\hline Iatrogenic & $\begin{array}{l}\text { Splenectomy, Cholecystectomy and other } \\
\text { abdominal surgery }\end{array}$ \\
\hline Others & $\begin{array}{l}\text { Idiopathic, Cirrhosis of liver, Portal } \\
\text { hypertension. }\end{array}$ \\
\hline
\end{tabular}

\section{Diagnostic Imaging}

Preferred diagnostic examinations in the setting of suspected PVT include Doppler ultrasonography, CT and magnetic resonance angiography. Non-visualization of the portal vein is strongly suggestive of occlusion. Portal venous thrombus may be partial

Table 2: Risk factors for Portal vein thrombosis. or complete. It may have a mixed acute and chronic appearance as well. Of note, a tumor invading the portal vein may have an appearance like that of venous thrombosis but is far less common. Tumor invasion of the portal vein is most frequently seen in cases of hepatocellular carcinoma.

\section{Management of Portal Vein Thrombosis}

Most patients with PVT are treated with immediate anticoagulation therapy. This is most often performed through continuous intravenous heparin infusion (Table 2), but some prefers using low-molecular-weight heparin. Chronic treatment options include warfarin or low-molecular-weight heparin. Anticoagulation should be maintained for at least 6 months and may need to be continued beyond that period depending on the cause of thrombosis. Other more invasive treatment modalities used in the setting of PVT include trans jugular catheterization of occluded veins, local thrombolytic infusion directly into the area of thrombosis or into the superior mesenteric artery, the creation of a trans jugular portosystemic shunt, stent implantation, and mechanical thrombectomy [4]. The experience with interventional techniques in the setting of PVT is still limited, and the benefit of these procedures remains to be fully defined [5-8]. There are, however, an increasing number of case reports that document the successful use of interventional radiology for both mechanical and pharmacologic thrombolysis in the setting of PVT [5-8]. For example, the use of percutaneous transhepatic catheterization with mechanical and pharmacologic thrombolysis [7]. They recommend that mechanical thrombectomy be performed first followed by local pharmacologic thrombolysis to achieve enhanced dissolution of the thrombus. Surgical interventions such as thrombectomy or shunting are certainly more invasive and are associated with their own set of complications [8].

\begin{tabular}{|c|c|c|c|}
\hline & $\begin{array}{l}\text { Conservative management } \\
\text { with no anticoagulation or } \\
\text { interventions }\end{array}$ & $\begin{array}{c}\text { Anticoagulation (LMWH/ } \\
\text { Warfarin/DOAC) }\end{array}$ & $\begin{array}{l}\text { Thrombectomy and/or } \\
\text { thrombolysis }\end{array}$ \\
\hline $\begin{array}{l}\text { Acute non-cirrhotic, non-malignant } \\
\text { PVT }\end{array}$ & $\begin{array}{l}\text { Asymptomatic cases with provoked } \\
\text { PVT (post-abdominal infections and } \\
\text { surgeries) with minimal thrombus } \\
\text { burden, and not involving other } \\
\text { venous segments. } \\
\text { Very high risk of bleeding on } \\
\text { anticoagulation or contraindication } \\
\text { to active bleeding. } \\
\text { Poor prognosis with other co- } \\
\text { morbidities. }\end{array}$ & $\begin{array}{l}\text { All symptomatic cases with } \\
\text { with concomitant PVT extension } \\
\text { into mesenteric or splenic veins. } \\
\text { Irreversible risk factors or } \\
\text { persistent hypercoagulable states. } \\
\text { Risk of increase in thrombus } \\
\text { burden while not anticoagulated. }\end{array}$ & $\begin{array}{l}\text { - Worsening abdominal pain with } \\
\text { thrombus extension with failed } \\
\text { anticoagulation therapy } \\
\text { - Impending intestinal necrosis and } \\
\text { infarction from venous thrombosis } \\
\text { seen with multiple splanchnic veins } \\
\text { thrombus }\end{array}$ \\
\hline PVT in cirrhosis & $\begin{array}{c}\text { •Asymptomatic cases with partial } \\
\text { non-obstructive PVT with no } \\
\text { involvement of other } \\
\text { venous segments and not awaiting } \\
\text { liver transplantation. } \\
\text { • Very high risk of bleeding on } \\
\text { anticoagulation or contraindication } \\
\text { to active bleeding }\end{array}$ & $\begin{array}{c}\text { All symptomatic cases with } \\
\text { with concomitant PVT extension } \\
\text { into mesenteric or splenic veins. } \\
\text { Irreversible risk factors or } \\
\text { persistent hypercoagulable states. }\end{array}$ & $\begin{array}{l}\text { - Worsening abdominal pain with } \\
\text { thrombus extension with failed } \\
\text { anticoagulation therapy } \\
\text { - Impending intestinal necrosis and } \\
\text { infarction from venous thrombosis } \\
\text { seen with multiple splanchnic veins } \\
\text { thrombus. }\end{array}$ \\
\hline
\end{tabular}




\begin{tabular}{|c|c|c|c|}
\hline & $\begin{array}{l}\text { - Poor prognosis with other } \\
\text { co-morbidities or end-stage liver } \\
\text { cirrhosis }\end{array}$ & $\begin{array}{l}\text { Risk of increase in thrombus } \\
\text { burden while not anticoagulated } \\
\text { Awaiting liver transplantation. }\end{array}$ & $\begin{array}{l}\text { - worsening portal hypertension } \\
\text { and its symptoms - Consider TIPS }\end{array}$ \\
\hline PVT in malignancy & $\begin{array}{c}\text {-Asymptomatic cases with partial } \\
\text { non-obstructive PVT with no } \\
\text { involvement of other venous } \\
\text { segments and not awaiting liver } \\
\text { transplantation. } \\
\text { • Very high risk of bleeding on } \\
\text { anticoagulation or contraindication } \\
\text { to active bleeding } \\
\text { • Poor prognosis with other co- } \\
\text { morbidities or end-stage } \\
\text { liver cirrhosis and not being } \\
\text { considered for liver transplantation }\end{array}$ & - Majority of patients & $\begin{array}{l}\text { - Worsening abdominal pain with } \\
\text { thrombus extension with failed } \\
\text { anticoagulation therapy } \\
\text { - Impending intestinal necrosis and } \\
\text { infarction from venous thrombosis } \\
\text { seen with multiple splanchnic veins } \\
\text { thrombus. }\end{array}$ \\
\hline
\end{tabular}

\section{Our Experience}

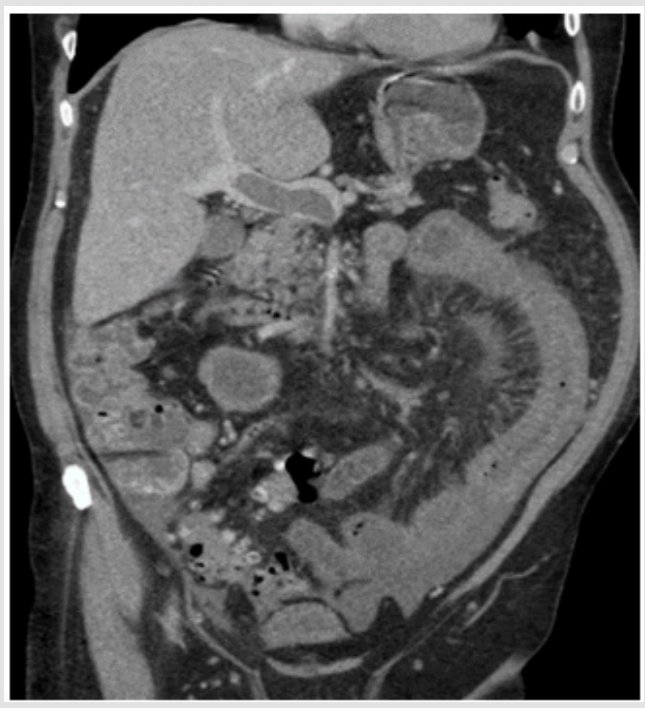

Figure 1: Thrombosis of Portal vein.

Interestingly, two patients who were presented on the same day in our surgical department with severe central abdominal pain and vomiting further investigation with CT abdomen shows PVT with no underlying liver pathology. Our first patient was a 71 years male presented with 3 days history coffee ground vomiting with severe central abdominal pain associated with diarrhea, malena and a dark colored urine with no other specific complaints otherwise his bowel and bladder habits were normal. He is otherwise fit and well with no significant family history. On examination his abdomen is soft and tenderness in RIF and suprapubic region, no distension, not peritinitic, no organomegaly and no palpable mass. Bloods shows mild raise in urea and CRP with no drop in hemoglobin at the time of presentation, so we organized a CT scan and shows PV, SMV, thrombosis (Figures 1 \& 2). Later he became hemodynamically unstable with mild peritonitic abdomen. He was then taken to theatre for diagnostic laparoscopy later converted to mini laparotomy under GA. Intra operative shows Serosanginuous free fluid in all the quadrants of abdomen and pelvis dilated proximal jejunum with oedematous and inflamed bowel wall, short segment of jejunum of about $25 \mathrm{~cm}$ congested, oedematous, thick inflamed wall but viable with good peristalsis, no signs of bowel ischemia or patchy necrosis present, mesentery of the jejunum is oedematous and inflamed, rest of the small bowel is healthy, appendix and large bowel were normal, solid viscera are normal. Peritoneal lavage was given and a drain is placed. As the segment of the congested jejunum is viable with good peristalsis, it was decided not to do any bowel resection. He did considerably well in the post-operative period was discharged on subcutaneous enoxaparin, with regular followup from the gastrointestinal and hematological point of view.

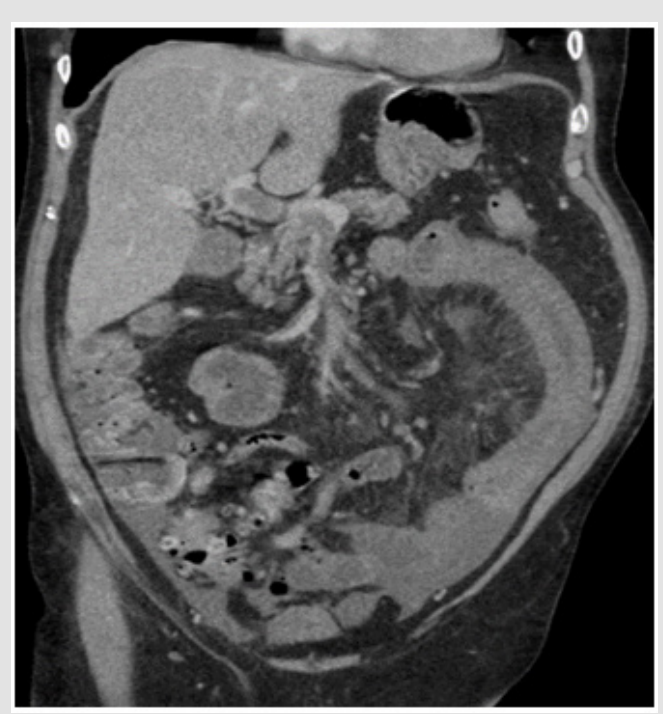

Figure 2: Thrombosis of SMV.

The second patient was a 58 years male presents with 1-week history of central abdominal pain radiating to back with no other significant history. His bowel and bladder habits are normal, no blood or malema in stools. He had a past medical history of DM and High cholesterol with no significant family history. On examination, his abdomen was soft, non-tender, no distension, not peritonitic, no organomegaly and no palpable mass. Bloods shows mild raise in CRP. CT scan shows Extensive thrombosis of portal vein, superior mesenteric vein, and its tributaries (Figures 3-5). He was admitted in general surgery and was started on heparin infusion. Both the patient presented with PVT without any liver pathology. 


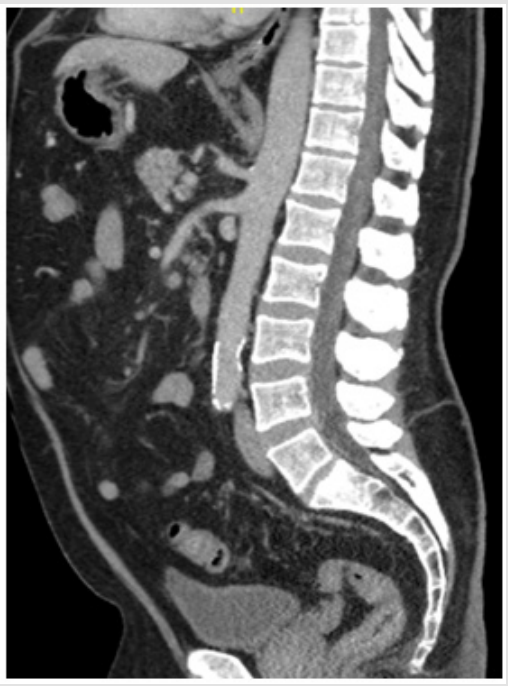

Figure 3: Superior Mesenteric Vein Thrombosis.

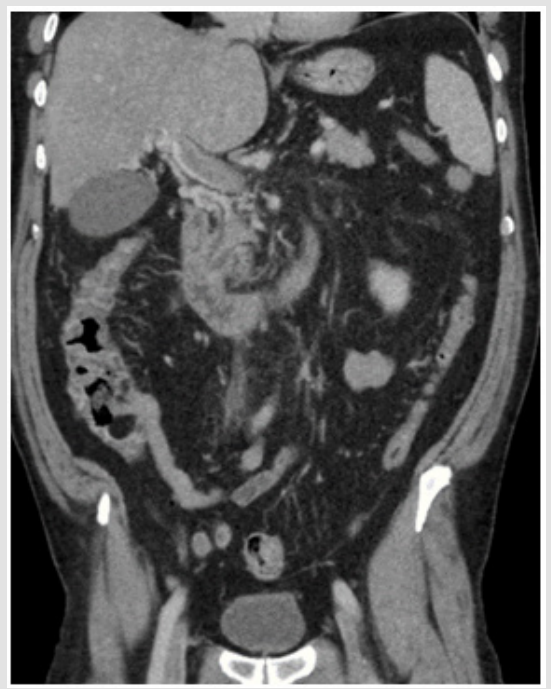

Figure 4: Portal vein thrombosis.

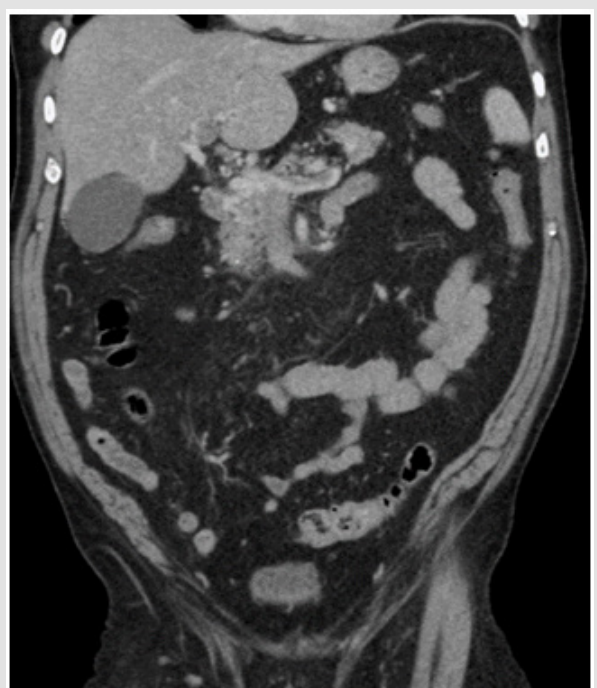

Figure 5: Splenic vein thrombosis.

\section{Discussion}

Initially, PVT occurs as a complication of some liver pathology like cirrhosis and hepatocellular carcinoma [3]. Now a day, it presents with several thrombophilic factors with local abdominal conditions. The main cause of PVT can be acquired or inherited. This can be classified as localised or systemic complications. The local causes are cirrhosis, malignancy like hepatocellular carcinoma gastric and pancreatic adenocarcinomas, cholangiocarcinoma, lymphoma, Abdominal infections like Bacteremia (e.g. Bacteroides fragilis), Inflammatory conditions like Pancreatitis, cholecystitis, diverticulitis, cholangitis, appendicitis, peptic ulcer perforation, inflammatory bowel diseases, Injury to portal vein during abdominal surgery (cholecystectomy, splenectomy, gastric bypass surgery, colectomy), trauma, shunts, liver transplant [9]. The systemic complications like Inherited thrombophilia like Factor V Leiden mutation, Prothrombin gene mutation, Protein C, S and AT deficiency, Hyperhomocystinemia, Acquired thrombophilia like Myeloproliferative disorders, JAK2 mutation (JAK2V617F) essential thrombocythemia, polycythemia vera, myelofibrosis, Antiphospholipid antibody syndrome/lupus anticoagulant, Pregnancy, Hormonal therapies, Non-abdominal malignancy, Paroxysmal nocturnal hemoglobinuria [3].

The presentation of the symptoms may vary from acute to chronic, If it occurs less than 60 days then its acute and more than 60 days, it is chronic [10]. Sometimes acute conditions are asymptomatic, but usually it is presented with acute abdominal pain, nausea and vomiting, hypotension and even death depending on the severity of it extend and its rapidity of the thrombus. If it is associated with superior mesenteric vein thrombus, it presents with mesenteric ischemia, haematochezia, fever, rebound tenderness, and ascites which is associated with a poor prognosis [11]. Acute PVT may undergo spontaneous resolution, or it may progress to chronic thrombosis. Chronic PVT may also be asymptomatic and can be incidental finding on imaging. But in chronic setting, it can present with symptoms of portal hypertension such as esophageal varices with bleeding, splenomegaly or hypersplenism, and ascites. The abdominal ultrasound (US) is the investigation of choice for PVT but more information can then be obtained through other imaging modalities like Doppler US, CT scan, magnetic resonance angiography and endoscopic ultrasound. Sonological findings usually include the presence of solid echoes within the portal vein and presence of a portal cavernoma [12]. But in our patient, the diagnosis was made by CT scan. CT scan can also be used to differentiate between recent and old thrombosis; the presence of portosystemic collaterals and cavernoma formation are both suggestive of old thrombosis [13]. The treatment for PVT is multifactorial; depending upon associated vessels involved and comorbidities, treatment options varies between conservative management to anticoagulation to thrombectomy and/or thrombolysis. 
Asymptomatic cases with provoked PVT like post-abdominal infections, post abdominal surgeries with minimal thrombus burden, or with partial non-obstructive PVT and not involving other venous segments except for portal vein and not awaiting liver transplantation, very high bleeding risk on anticoagulation or active bleeding not yet corrected other related short-term, poor prognosis co-morbidities or end-stage liver cirrhosis are all treated with Conservative management with no anticoagulation or interventions [14]. All Symptomatic cases with concomitant PVT with extension into mesenteric or splenic veins with non-reversible risk factors or persistent hypercoagulable states interval or increase in thrombus burden while not anticoagulated or waiting for liver transplantation were all treated with anti-coagulants [15] (Table 2). All patients with Worsening abdominal pain with thrombus extension with failed anticoagulation therapy and impending intestinal necrosis and infarction from venous thrombosis seen with multiple splanchnic veins thrombus all treated with thrombectomy and/or thrombolysis and with worsening portal hypertension and its symptoms should be considered for Trans jugular Intrahepatic Portosystemic Shunt (TIPS). For the patient with variceal bleeding the use of beta blockers can be considered as a prophylactic treatment and has successfully reduced the rate of the first variceal bleed and many studies have shown that variceal band ligation (VBL) is as effective as beta blockers [16,17].

\section{Conclusion}

PVT is an important entity that all surgeons should be familiar with. There are many associated risk factors for the development of PVT. In suspected cases, Doppler ultrasonography and/or CT imaging of the abdomen are the most effective diagnostic tool. Anticoagulation is the principal method of treating this condition. Interventional radiologic techniques, including mechanical thrombectomy, thrombolysis, and stenting, are becoming more popular. Open surgical approaches are often difficult and plagued by significant associated morbidity. Long-term prognosis of PVT is good in patients without underlying malignancy or cirrhosis.

\section{Conflict of Interests}

The authors declare that there is no conflict of interest.

\section{References}

1. Ogren M, Bergqvist D, Björck M (2006) Portal vein thrombosis: prevalence, patient characteristics and lifetime risk: a population study based on 23,796 consecutive autopsies. World J Gastroenterol 12(13): 2115-2119.
2. Zocco MA, Di Stasio E, De Cristofaro R, Novi M, Ainora ME, et al. (2009) Thrombotic risk factors in patients with liver cirrhosis: correlation with MELD scoring system and portal vein thrombosis development. J Hepatol 51(4): 682-689.

3. Dentali F, Galli M, Gianni M (2008) Inherited thrombophilic abnormalities and risk of portal vein thrombosis: a metaanalysis. Thromb Haemost 99(4): 675-682.

4. Rivitz SM, Geller SC, Hahn C, Waltman AC (1995) Treatment of acute mesenteric venous thrombosis with transjugular intramesenteric urokinase infusion. J Vasc Interv Radiol 6: 219-223.

5. Ozkan U, Oğuzkurt L, Tercan F, Tokmak N (2006) Percutaneous transhepatic thrombolysis in the treatment of acute portal venous thrombosis. Diagn Interv Radiol 12(2): 105-107.

6. Poplausky MR, Kaufman JA, Geller SC, Waltman AC (1996) Mesenteric venous thrombosis treated with urokinase via the superior mesenteric artery. Gastroenterology 110: 1633-1635.

7. Rossi C, Zambruni A, Ansaloni F, Casadei A, Morelli C, et al. (2004) Combined mechanical and pharmacologic thrombolysis for portal vein thrombosis in liver-graft recipients and in candidates for liver transplantation. Transplantation 78(6): 938-940.

8. Ryu R, Lin TC, Kumpe D, Krysl J, Durham JD, et al. (1998) Percutaneous mesenteric venous thrombectomy and thrombolysis: Successful treatment followed by liver transplantation. Liver Transpl Surg 4(3): 222-225.

9. Rajani R, Bjornsson E, Bergquist A (2010) The epidemiology and clinical features of portal vein thrombosis: a multicentre study. Aliment Pharmacol Ther 32(9): 1154-1162.

10. Liappis AP, Roberts AD, Schwartz AM (2003) Thrombosis and infection: a case of transient anti-cardiolipin antibody associated with pylephlebitis. Am J Med Sci 325(6): 365-368.

11. Malkowski P, Pawlak J, Michalowicz B (2003) Thrombolytic treatment of portal thrombosis. Hepatogastroenterology 50(54): 2098-2100.

12. Gertsch P, Matthews J, Lerut J, Luder P, Blumgart LH (1993) Acute thrombosis of the splanchnic veins. Arch Surg 128(3): 341-345.

13. Tripodi A, Mannucci PM (2011) The coagulopathy of chronic liver disease. N Engl J Med 365(2): 147-156.

14. Kanellopoulou T, Alexopoulou A, Theodossiades G (2010) Pylephlebitis: an overview of non-cirrhotic cases and factors related to outcome. Scand J Infect Dis 42(11-12): 804-811.

15. Baril N, Wren S, Radin R (1996) The role of anticoagulation in pylephlebitis. Am J Surg 172(5): 449-452.

16. Amitrano L, Guardascione MA, Brancaccio V (2004) Risk factors and clinical presentation of portal vein thrombosis in patients with liver cirrhosis. J Hepatol 40(5): 736-741.

17. Yu D, Turner JR (2008) Interdigitation of TJ proteins (occludin and claudin) and their attachment to the sliding actin-myosin complex via plaque proteins (e.g Z01, Z02/3). Stimulus-induced reorganization of tight junction structure: The role of membrane traffic. Biochimica et Biophysica Acta (BBA) 1778(3): 709-716. 
ISSN: 2574-1241

DOI: $10.26717 /$ BJSTR.2020.29.004747

M Miah. Biomed J Sci \& Tech Res

(C) This work is licensed under Creative

Submission Link: https://biomedres.us/submit-manuscript.php

$\begin{array}{ll}\text { BIOMEDICAL } & \text { Assets of Publishing with us } \\ \text { RESEARCHES } & \text { - Global archiving of articles } \\ \text { - Immediate, unrestricted online access } \\ \text { - Rigorous Peer Review Process } \\ \text { - Authors Retain Copyrights }\end{array}$

